\title{
The Optimality of the Friedman Rule When Some Distorting Taxes Are Exogenous
}

\author{
Alexandre B. Cunha* \\ Ibmec Business School \\ abcunha@ibmecrj.br \\ http://professores.ibmecrj.br/abcunha
}

May 8, 2005

\begin{abstract}
This paper investigates the optimality of the Friedman rule in a two-sector small open economy. That policy prescription is found to be a necessary condition for Pareto efficiency. If a planner can select all conceivable distorting taxes, then, for some initial values of public debt, money balances and foreign assets, it is possible to decentralize a Pareto efficient allocation. If the planner can select only some of these tax rates, then second-best policies may also satisfy the Friedman rule. However, this last result depends on the set of tax instruments the planner can choose from.
\end{abstract}

Keywords: Friedman rule, optimal taxation, open economy.

JEL classification: E31, E52, E63, H21.

\section{Introduction}

In a seminal essay, Friedman [9] suggested that a government should set the nominal interest rate equal to zero to lead the economy to an efficient outcome. He argued that only such a policy would achieve maximization of the consumer surplus associated with money demand. That policy prescription became known in the literature as the Friedman rule.

Phelps [14] pointed out that Friedman's argument was a partial equilibrium one and implicitly relied on the availability of lump-sum taxes. Phelps

\footnotetext{
*Previous versions of this paper circulated under the title "The Friedman Rule in a Two Sector Small Open Economy." It highly benefited from comments by participants of the 2004 North American Summer Meeting of the Econometric Society and the 2003 Meeting of the Brazilian Econometric Society and participants of workshops at Pontifical Catholic University of Rio de Janeiro and the University of São Paulo. Of course, the usual disclaimer applies. Financial support from the Brazilian Council of Science and Technology (CNPq) and the Carlos Chagas Filho Foundation for Research Support (FAPERJ) is gratefully acknowledged.
} 
Alexandre B. Cunha

also argued that in a general equilibrium setup without lump-sum taxation the Friedman rule was likely not to be optimal. The reason for this would be the fact that a second-best policy generally would encompass using all available distorting taxes, including inflation.

Lucas and Stokey [12] were the first to show that the optimality of the Friedman rule could also hold in a general equilibrium context, provided that the government had access to lump-sum revenues. Later, Kimbrough [11] showed that the Friedman rule could be optimal even if all source of tax revenues were distorting ones. After Lucas and Stokey's and Kimbrough's papers, a large body of literature addressed the optimality of the Friedman rule when all tax revenue sources are distorting. Relatively recent papers on that subject are Carlstrom and Fuerst [1]; Cavalcanti and Villamil [2]; Chari, Christiano and Kehoe [3]; Cole and Kocherlakota [5]; Correia and Teles [6] and [7]; De Fiore and Teles [8]; Ireland [10]; and Schmitt-Grohé and Uribe [16] and [17].

Chari, Christiano and Kehoe [3] studied the optimality of the Friedman rule in a one-sector model with three distinct types of monetary frictions: cashcredit, money in the utility function and shopping time. The only distorting tax available in their models is on labor income. They found that in the first two cases, for standard preferences, the Friedman rule is optimal. In the shopping time case, Friedman's prescription is optimal whenever the transaction technology is homogenous of degree one or higher.

Correia and Teles [6] characterized the optimal interest rate policy in a onesector shopping time economy with distorting taxes on labor income. They generalized one of the results that Chari, Christiano and Kehoe [3] had obtained by showing that the Friedman rule is an optimal policy for a transaction technology that is homogenous of any degree. In a later work, Correia and Teles [7] showed that, under some conditions of the period utility function, the Friedman rule is optimal in a money in the utility function setup. In the same paper, they also showed, by means of a calibration exercise, that if their assumption on preferences were not satisfied, the optimal interest rate would be positive but small (less than $1 \%$ per year).

Recently, De Fiore and Teles [8] found that the result obtained by Correia and Teles [6] did not depend on whether the Ramsey planner could use distorting taxes on labor income or consumption or both. They found the Friedman rule to be optimal whenever the transaction technology is restricted to ensure that the elasticity of the money demand is unit elastic with respect to the gross price of the consumption good. They argued that restriction is an intuitive one, since, from a household point of view, the relevant measure of real balances is given by the ratio of nominal cash holdings to the gross price level.

A main lesson that emerges from Chari, Christiano and Kehoe [3]; Correia and Teles [6] and [7]; and De Fiore and Teles [8] is that the optimality of the Friedman rule does not critically rely on any specific type of monetary friction. For standard preferences and technologies, that policy prescription is optimal in cash-in-advance, money in the utility function and shopping time economies. Whenever it fails to be optimal, the deviations are quantitatively small.

The findings listed in the above paragraph apparently make a strong case 
The Optimality of the Friedman Rule

for the Friedman rule. However, as we shall see, those findings depend on the implicit hypothesis that the planner has access to a sufficiently large set of distorting tax instruments.

Carlstrom and Fuerst [1] found that the Friedman rule may fail to be optimal in a small open economy. According to them, the failure is due to the existence of an exogenous international interest rate that impacts the behavior of domestic agents and constrains the choices of the Ramsey planner in such way that it is optimal to deviate from the Friedman rule.

Cavalcanti and Villamil [2] studied the problem of selecting the optimal monetary and fiscal policy in an economy with an informal (untaxed) sector. They concluded that in such a context the Friedman rule fails to be optimal. Additionally, the deviations from it can be quantitatively large.

Schmitt-Grohé and Uribe [16] investigated the optimality of the Friedman rule in a one-sector small open economy. In their model, Friedman's prescription is optimal only if the Ramsey planner is able to use consumption taxes. Otherwise, the Friedman rule fails to be optimal and the deviations can be numerically sizable.

A venue to clarify the contradictory findings concerning the optimality of the Friedman rule is to take a deeper look at the set of distorting taxes available to the planner. This issue was obscured in other papers because of the simplicity of the models. In more sophisticated economies, the relevance of the number of available tax instruments becomes obvious.

To better understand this point, consider the cash-credit model in Chari, Christiano and Kehoe [3]. In that simple single sector, single input and constant return to scale economy, there exist only two possible distorting taxes: on consumption $\left(\tau^{c}\right)$ and on labor income $\left(\tau^{l}\right)$. If the planner can select both $\tau^{c}$ and $\tau^{l}$, then it may be possible to decentralize the unique Pareto efficient allocation (a necessary condition for this is that the initial real net government debt not be zero). Any policy that decentralizes that allocation will display the Friedman rule as one of its features. Whenever the planner can pick only one of the two taxes, the Friedman rule is a component of the second-best policy. If the planner can select none of them, then the Friedman rule is unlikely even to be attainable (since its implementation requires a fiscal surplus that finances the contraction of the money supply). For this reason, in this paper we do not consider the case in which all tax rates are exogenous.

Consider now a situation in which there are three possible generic distorting taxes $\left(\tau^{1}, \tau^{2}\right.$ and $\left.\tau^{3}\right)$. Clearly, there exist many more cases to be studied. In fact, there are seven cases to be looked into. Each of these cases is a non-empty subset of $\left\{\tau^{1}, \tau^{2}, \tau^{3}\right\}$. One can think of the non optimality of the Friedman rule in Carlstrom and Fuerst [1], Cavalcanti and Villamil [2] and Schmitt-Grohé and Uribe [16] simply as its non optimality for a particular subset of all conceivable distorting taxes that could possibly be implemented in their economies.

The above discussion naturally guides us to inquire about the optimality of the Friedman rule when the Ramsey planner is constrained to choose some, but not all, of several possible distorting taxes. This is the problem we study in this paper. We investigate whether the Friedman rule is optimal or not under 
Alexandre B. Cunha

different assumptions on the ability of the planner to select distorting tax rates.

To make our exercise an interesting one, we cannot restrict ourselves to a standard one-sector monetary model. Therefore, we adopt a two-sector (tradable and non-tradable) small open economy. Consumers face a cash-in-advance constraint on a fraction of their purchases of non-tradables. There is distorting taxation on labor income, private consumption of each type of good and foreign interest income. As usual, government consumption is exogenous. We performed several exercises in which the planner cannot choose all of these taxes. This allows for a deeper understanding of the relation between the optimality of the Friedman rule and the availability of tax instruments.

Of course, not only open economies have many sectors, goods and taxes. We chose to consider an open economy for two reasons. First, actual economies are open economies. Hence, our choice brings us closer to the actual decisions that policy makers face in the real world. Second, there already exist some papers that study the optimality of the Friedman rule in open economies, such as Carlstrom and Fuerst [1] and Schmitt-Grohé and Uribe [16] and we want to relate our findings to theirs.

We now report our main conclusions. As usual, the Friedman rule is a necessary condition for Pareto efficiency. For some values of cash, public debt and foreign asset holdings, if a planner can select all possible distorting taxes, it is possible to implement the unique Pareto efficient allocation. If the planner cannot select all available tax rates, then the Friedman rule may or may not be optimal. Its optimality depends on which subset of distorting taxes the planner can choose from. Particularly, if the planner can select the tax rate on the consumption of non-tradables the Friedman rule is optimal. Plus, there exist some particular cases in which the Friedman rule is optimal, even though the tax rate on the consumption of non-tradables is exogenous.

Given the above conclusion, we identify three contributions in this paper. First, we showed that the Friedman rule can be optimal in environments richer than the standard one-sector closed economy in which it is usually evaluated. Second, we showed that the non optimality of the Friedman identified by other authors is a consequence of some very specific restrictions imposed on the ability of the Ramsey planner to set the level of some conceivable distorting taxes. Third, we showed that the optimality of the Friedman rule cannot be assessed without looking into possible restrictions that the government faces when setting distorting taxes; particularly, we provided theoretical grounds to assume that it is optimal whenever the Ramsey planner has access to consumption taxes.

We should emphasize that the general nature of the results we present in this paper does not rely on the type of monetary friction considered. The facts that the Friedman rule is a necessary condition for Pareto efficiency and that the optimality of a zero nominal interest rate depends on the exact restrictions the Ramsey planner faces when selecting the policies do not depend on whether money is introduced by means of a cash-in-advance or shopping time or money in the utility function friction.

This paper is organized as follows. Section 2 describes the model economy. Section 3 is devoted to the characterization of the set of competitive equilibria. 
The Optimality of the Friedman Rule

Section 4 characterizes the Pareto efficient allocation and discusses its implementation. Section 5 discusses the optimal policies when the first-best Pareto allocation cannot be implemented. Concluding remarks are found in Section 6 . Proofs and some other technical issues are found in the Appendix.

\section{The economy}

Consider a small country populated by a single infinitely lived household and a government. The household is composed by a shopper and a worker, who are endowed with one unit of time.

The country produces a non-tradable good. The household and the government consume that good. The respective amounts they consume of it are denoted by $c^{N}$ and $g^{N}$. The country also produces a tradable good. The household and the government consume it; the respective notations are $c^{T}$ and $g^{T}$. The country can export or import this last good; $x$ denotes the amount exported. As usual, a negative value for $x$ means that the country is importing the tradable good.

Markets operate in a particular way. At a first stage of each date $t$, a spot market for goods and labor services operates. At a second stage, after the market for goods and labor service closes, a security and currency market operates. ${ }^{1}$

A domestic currency $M$ circulates in this economy. Agents trade two types of securities: a claim $B$ that pays $(1+i)$ units of $M$ and a claim $B^{F}$ that pays $\left(1+i_{t}^{F}\right)$ units of some foreign currency. Both claims mature after one period. Foreigners do not sell or buy claims to the domestic currency and $i_{t}^{F}$ is exogenous.

The worker cannot sell her services outside the country. The shopper faces a cash-in-advance constraint. A fraction $c_{1}^{N}$ of the her purchase of $c^{N}$ must be paid for with the domestic currency. All other transactions are liquidated during the security and currency trading session. The date $t$ price, in terms of the foreign currency, of the tradable good is exogenous and equal to one.

The inequalities $0 \leq y^{T} \leq\left(l^{T}\right)^{\alpha^{T}}$ and $0 \leq y^{N} \leq\left(l^{N}\right)^{\alpha^{N}}$, where $y^{i}$ is the output of good $i \in\{T, N\}$, and $l^{i}$ is the amount of labor allocated to its production, describe the technology. Both $\alpha^{T}$ and $\alpha^{N}$ lie in the set $(0,1]$.

A finite set $G^{T} \times G^{N} \times I^{F}$ contains the sequence $\left\{g_{t}^{T}, g_{t}^{N}, i_{t}^{F}\right\}_{t=0}^{\infty}$. Additionally, $G^{T} \subset \mathbb{R}_{+}, G^{N} \subset \mathbb{R}_{+}$and $I^{F} \subset \mathbb{R}_{++}$.

A single competitive firm produces each good. Let $l_{t}$ denote the amount of labor the household supplies at date $t$. Other variables indexed by $t$ have analogous meanings. Feasibility requires

$$
l_{t}^{T}+l_{t}^{N}=l_{t} \leq 1, c_{1 t}^{N}+c_{2 t}^{N}+g_{t}^{N}=\left(l_{t}^{N}\right)^{\alpha^{N}}, c_{t}^{T}+g_{t}^{T}+x_{t}=\left(l_{t}^{T}\right)^{\alpha^{T}} .
$$

\footnotetext{
${ }^{1}$ The timing convention we adopted implies that unexpected inflation does not act as a lump sum tax. Hence, the problem of selecting an optimal policy will have a well-defined solution even if the government has some outstanding debt at date zero. This allows us not to assume any pair of values for initial debt and cash holdings. See Nicolini [13] and Svensson [18] for further details on this timing convention. We want to emphazise that none of the results presented in this paper depend on the timing convention adopted.
} 
The government finances the sequence $\left\{g_{t}^{T}, g_{t}^{N}\right\}_{t=0}^{\infty}$ by issuing and withdrawing the domestic currency; by issuing and redeeming claims $B$ of maturity of one period to $1+i$ units of the domestic currency; by purchasing and selling $B^{F}$; and by taxing profits, labor income, consumption and interest income on foreign assets. The government budget constraint is

$$
\begin{gathered}
E_{t} g_{t}^{T}+p_{t}^{N} g_{t}^{N}+E_{t} B_{G t+1}^{F}+\left(1+i_{t}\right) B_{t}+M_{t}= \\
E_{t}\left(1+i_{t}^{F}\right) B_{G t}^{F}+M_{t+1}+B_{t+1}+\tau_{t}^{l} w_{t} l_{t}+\tau_{t}^{T} E_{t} c_{t}^{T}+ \\
\tau_{t}^{N} p_{t}^{N}\left(c_{1 t}^{N}+c_{2 t}^{N}\right)+E_{t} \delta_{t}^{F} i_{t}^{F} B_{H t}^{F}+\delta_{t}^{T} \psi_{t}^{T}+\delta_{t}^{N} \psi_{t}^{N},
\end{gathered}
$$

where $E_{t}$ is the nominal exchange rate; $p_{t}^{N}$ and $w_{t}$ are the respective date $t$ monetary prices (in terms of the domestic currency) of the non-tradable good and labor services; $B_{G t+1}^{F}$ stands for the foreign assets held by the government at the end of date $t$, while $B_{H t}^{F}$ is people's foreign assets at the beginning of the same period; $M_{t+1}$ and $B_{t+1}$ are the amounts of domestic currency and public debt held by the household at the end of date $t ; i_{t}$ is the nominal domestic interest rate; $\psi_{t}^{T}$ and $\psi_{t}^{N}$ are the date $t$ profits; $\tau_{t}^{l}, \tau_{t}^{T}$ and $\tau_{t}^{N}$ are tax rates on labor income and consumption; $\delta_{t}^{F}$ is the tax rate on household's foreign assets income; and $\delta_{t}^{T}$ and $\delta_{t}^{N}$ are the tax rates on profits. A negative value for $B_{G t+1}^{F}$ means that the government is borrowing abroad, while a negative value for $B_{t+1}$ means that the government is lending to domestic residents. At $t=0$ the government holds an initial amount $B_{G 0}^{F}$ of foreign assets. To avoid Ponzi schemes, a standard boundedness constraint $\left|B_{G, t+1}^{F}\right| \leq A<\infty$ is imposed on government foreign assets.

The function $u: \mathbb{R}_{+}^{3} \times[0,1] \rightarrow \mathbb{R} \cup\{-\infty\}$,

$$
u=u\left(c^{T}, c_{1}^{N}, c_{2}^{N}, l\right),
$$

is the household period utility function. It displays local non-satiability and satisfies standard differentiability and Inada conditions. As usual, intertemporal preferences are described by

$$
\sum_{t=0}^{\infty} \beta^{t} u\left(c_{t}^{T}, c_{1 t}^{N}, c_{2 t}^{N}, l_{t}\right)
$$

where $\beta \in(0,1)$. The date $t$ budget constraint of the household is

$$
\begin{gathered}
\left(1+\tau_{t}^{T}\right) E_{t} c_{t}^{T}+\left(1+\tau_{t}^{N}\right) p_{t}^{N}\left(c_{1 t}^{N}+c_{2 t}^{N}\right)+M_{t+1}+ \\
B_{t+1}+E_{t} B_{H t+1}^{F} \leq\left(1-\tau_{t}^{l}\right) w_{t} l_{t}+M_{t}+\left(1+i_{t}\right) B_{t} \\
E_{t}\left[1+\left(1-\delta_{t}^{F}\right) i_{t}^{F}\right] B_{H t}^{F}+\left(1-\delta_{t}^{T}\right) \psi_{t}^{T}+\left(1-\delta_{t}^{N}\right) \psi_{t}^{N} .
\end{gathered}
$$

The constraint $\left|\frac{B_{t+1}}{E_{t+1}}\right|,\left|B_{H, t+1}^{F}\right| \leq A$ prevents Ponzi games. The household faces the cash-in-advance constraint

$$
\left(1+\tau_{t}^{N}\right) p_{t}^{N} c_{1 t}^{N} \leq M_{t}
$$


Given initial cash and bond holdings $\left(M_{0}, B_{0}, B_{H 0}^{F}\right)$, a household chooses a sequence $\left\{c_{t}^{T}, c_{1 t}^{N}, c_{2 t}^{N}, l_{t}, M_{t+1}, B_{t+1}, B_{H t+1}^{F}\right\}_{t=0}^{\infty}$ to maximize (4) subject to the constraints (5), (6), and $l_{t} \leq 1$. Additionally, the sequences $\left\{c_{t}^{T}\right\}_{t=0}^{\infty},\left\{c_{1 t}^{N}\right\}_{t=0}^{\infty}$, $\left\{c_{2 t}^{N}\right\}_{t=0}^{\infty}$ and $\left\{\frac{M_{t+1}}{E_{t+1}}\right\}_{t=0}^{\infty}$ are required to be bounded.

At each date $t$, the firm that produces the non-tradable good chooses $l_{t}^{N}$ to maximize $\psi_{t}^{N}=p_{t}^{N}\left(l_{t}^{N}\right)^{\alpha^{N}}-w_{t} l_{t}^{N}$. In a similar fashion, the other firm chooses $l_{t}^{T}$ to maximize $\psi_{t}^{T}=E_{t}\left(l_{t}^{T}\right)^{\alpha^{T}}-w_{t} l_{t}^{T}$.

\section{Competitive equilibrium}

We denote the date $t$ price vector $\left(E_{t}, p_{t}^{N}, w_{t}, i_{t+1}\right)$ by $\varphi_{t}$ and the sequence $\left\{\varphi_{t}\right\}_{t=0}^{\infty}$ by $\varphi$. The date $t$ vector of tax rates $\left(\tau_{t}^{l}, \tau_{t}^{N}, \tau_{t}^{T}, \delta_{t+1}^{F}, \delta_{t}^{N}, \delta_{t}^{T}\right)$ is denoted by $\xi_{t}$ and $\xi=\left\{\xi_{t}\right\}_{t=0}^{\infty}$ is a tax policy. Date $t$ allocations $\left(l_{t}^{N}, l_{t}^{T}, x_{t}, c_{t}^{T}, c_{1 t}^{N}, c_{2 t}^{N}, l_{t}\right)$ and end-of-period asset holdings $\left(M_{t+1}, B_{t+1}, B_{H t+1}^{F}, B_{G t+1}^{F}\right)$ are denoted, respectively, by $\chi_{t}$ and $\zeta_{t+1}$. Additionally, $\chi=\left\{\chi_{t}\right\}_{t=0}^{\infty}$ and $\zeta=\left\{\zeta_{t+1}\right\}_{t=0}^{\infty}$.

Definition 1 A competitive equilibrium for a tax policy $\xi$ is an object $(\varphi, \chi, \zeta)$ satisfying: (i) given $\varphi$ and $\xi,(\chi, \zeta)$ provides a solution for the household problem; (ii) given $\varphi_{t}, l_{t}^{N}$ and $l_{t}^{T}$ maximize the respective firm's profit; (iii) (1) and (2) hold. An array $(\xi, \varphi, \chi, \zeta)$ is attainable if $(\varphi, \chi, \zeta)$ is a competitive equilibrium for $\xi$.

Two points in the above definition should be emphasized. Item (ii) is equivalent to $w_{t}=p_{t}^{N} \alpha^{N}\left(l_{t}^{N}\right)^{\alpha^{N}-1}=E_{t} \alpha^{T}\left(l_{t}^{T}\right)^{\alpha^{T}-1}$. Adding the identities $\psi_{t}^{N}+w_{t} l_{t}^{N}=p_{t}^{N}\left(c_{1 t}^{N}+c_{2 t}^{N}+g_{t}^{N}\right)$ and $\psi_{t}^{T}+w_{t} l_{t}^{T}=E_{t}\left(c_{t}^{T}+x_{t}+g_{t}^{T}\right)$ to (2) and (5) taken as equality, one obtains

$$
x_{t}+\left(1+i_{t}^{F}\right)\left(B_{G t}^{F}+B_{H t}^{F}\right)-B_{G t+1}^{F}-B_{H t+1}^{F}=0,
$$

which is the balance-of-payments identity for this economy. So, it is not necessary to spell this condition out when defining competitive equilibrium.

Next we characterize the set of competitive equilibrium allocations in terms of few constraints. As previously mentioned, we want to study the problem of selecting optimal monetary policy and tax rates when some others tax rates are exogenous. Thus, our characterization will depend on the tax sequence $\xi$. As we allow the government to choose some of the tax rates, we can drop some of the constraints. We will elaborate further on this topic in Section 5.

To simplify the notation, $u(t), u_{T}(t), u_{1}(t), u_{2}(t)$, and $u_{l}(t)$ will denote, respectively, the value of $u$ and its partial derivatives $\partial u / \partial c^{T}, \partial u / \partial c_{1}^{N}, \partial u / \partial c_{2}^{N}$, and $\partial u / \partial l$ evaluated at the point $\left(c_{t}^{T}, c_{1 t}^{N}, c_{2 t}^{N}, l_{t}\right)$. The sum $u_{T}(t) c_{t}^{T}+u_{1}(t) c_{1 t}^{N}+$ $u_{2}(t) c_{2 t}^{N}+u_{l}(t) l_{t}$ will be denoted by $W(t)$.

There exist six conditions with obvious economic meaning that must hold in any competitive equilibrium. A trivial condition is (1). The second requirement, ensuring that people's intertemporal marginal rate of substitution is consistent 
with $i_{t}^{F}$ and tax rates, could be expressed as

$$
\beta \frac{u_{T}(t+1)}{u_{T}(t)}=\frac{1+\tau_{t+1}^{T}}{1+\tau_{t}^{T}} \frac{1}{1+\left(1-\delta_{t+1}^{F}\right) i_{t+1}^{F}} .
$$

However, for future convenience, we write that constraint as

$$
u_{T}(t)=\beta^{-t} \frac{1+\tau_{t}^{T}}{1+\tau_{0}^{T}} \frac{u_{T}(0)}{\prod_{s=1}^{t}\left[1+\left(1-\delta_{s}^{F}\right) i_{s}^{F}\right]},
$$

where the empty product $\prod_{s=1}^{0}$ is defined to be equal to one. The third constraint is that households' marginal rate of substitution between tradables and non-tradables must be consistent with the tax rates and the marginal rate of transformation between those types of goods, i.e.,

$$
\frac{u_{T}(t)}{u_{2}(t)}=\frac{1+\tau_{t}^{T}}{1+\tau_{t}^{N}} \frac{\alpha^{N}\left(l_{t}^{T}\right)^{1-\alpha^{T}}}{\alpha^{T}\left(l_{t}^{N}\right)^{1-\alpha^{N}}} .
$$

The fourth

$$
-\frac{u_{l}(t)}{u_{2}(t)}=\frac{1-\tau_{t}^{l}}{1+\tau_{t}^{N}} \frac{\alpha^{N}}{\left(l_{t}^{N}\right)^{1-\alpha^{N}}},
$$

is an implementability constraint for real wage. The fifth is

$$
\begin{gathered}
u_{1}(0) c_{1,0}^{N}+u_{2}(0)\left[\frac{\left(1+i_{0}\right) B_{0}}{\left(1+\tau_{0}^{N}\right) p_{0}^{N}}+\frac{M_{0}}{\left(1+\tau_{0}^{N}\right) p_{0}^{N}}-c_{1,0}^{N}\right]+ \\
u_{T}(0) \frac{\left[1+\left(1-\delta_{0}^{F}\right) i_{0}^{F}\right] B_{H 0}^{F}}{1+\tau_{0}^{T}}= \\
\sum_{t=0}^{\infty} \beta^{t}\left\{W(t)+\frac{u_{l}(t)}{\left(1-\tau_{t}^{l}\right)}\left[\left(1-\delta_{t}^{T}\right) \frac{1-\alpha^{T}}{\alpha^{T}} l_{t}^{T}+\left(1-\delta_{t}^{N}\right) \frac{1-\alpha^{N}}{\alpha^{N}} l_{t}^{N}\right]\right\},
\end{gathered}
$$

which consolidates all date $t$ budget constraints of the households. The sixth is a balance-of-payment constraint

$$
-\sum_{t=0}^{\infty} \frac{x_{t}}{\prod_{s=1}^{t}\left(1+i_{s}^{F}\right)}=\left(1+i_{0}^{F}\right)\left(B_{H 0}^{F}+B_{G 0}^{F}\right)
$$

which requires imports to be financed by the country's initial wealth.

The above constraints are not enough to characterize a competitive equilibrium. The inequalities

$$
\begin{gathered}
\left(1+\tau_{0}^{N}\right) p_{0}^{N} c_{1,0}^{N} \leq M_{0} \\
u_{2}(t) \leq u_{1}(t)
\end{gathered}
$$

are needed to ensure that cash-in-advance constraints hold. Finally, an implementability constraint for a transversality condition is

$$
\lim _{t \rightarrow \infty} \frac{\beta^{t} u_{1}(t) c_{1 t}^{N}}{\left(1+\tau_{t}^{N}\right)}=0
$$


The Optimality of the Friedman Rule

Proposition 1 Let $M_{0}>0$. A bounded sequence $\chi$ and a price $p_{0}^{N}>0$ satisfy (1) and (9)-(16) if and only if they are components of an attainable array $(\xi, \varphi, \chi, \zeta)$.

Proof. See Appendix.

The proof of Proposition 1 is a long but straightforward exercise. It is enough to modify the techniques that other authors (for instance, Chari, Christiano and Kehoe [3] or Lucas and Stokey [12]) used for one-sector closed economy models.

The above set of constraints does not include an implementability condition for the government budget constraint. However, there are implementability conditions for people's budget constraint, resource constraints and balance-ofpayments. Since the government budget constraint is a linear combination of those other constraints, it is not necessary to spell it out.

Let us now consider the constraints the Friedman rule places on the path of the money supply. The Friedman rule specifies that, for all $t$,

$$
i_{t+1}=0 .
$$

From people's first-order conditions, it is easy to conclude that $i_{t+1}=0$ if and only if $u_{2}(t+1)=u_{1}(t+1)$.

As pointed out by Cole and Kocherlakota [5], Ireland [10] and Wilson [19], (17) implies the following two conditions:

$$
\begin{aligned}
& \lim _{t \rightarrow \infty} M_{t}=0 ; \\
& \inf _{t} \frac{M_{t}}{\beta^{t}}>0 .
\end{aligned}
$$

Condition (18) simply states that the nominal quantity of money has to vanish in the long run, while (19) places a bound on its decay rate. The next proposition formalizes the above discussion.

Proposition 2 If a competitive equilibrium $(\varphi, \chi, \zeta)$ satisfies (17), then it satisfies (18) and (19).

Proof. See Appendix.

Cole and Kocherlakota [5] and Ireland [10] argue that the implementation of the Friedman rule leaves the path of nominal balances undetermined. The next proposition establishes that the same holds in the economy we consider in this paper.

Proposition 3 If a competitive equilibrium $(\varphi, \chi, \zeta)$ satisfies (17), then there are uncountably many $\zeta^{\prime}$ such that $\left(\varphi, \chi, \zeta^{\prime}\right)$ is a competitive equilibrium.

Proof. See Appendix. 
Alexandre B. Cunha

The intuition for the aforementioned indeterminacy is extremely simple. If the nominal interest rate is zero, people will be indifferent between domestic bonds and money, provided they have enough balances to purchase the desired amount of $c_{1}$. Thus, the government can carry out open market operations that increase the amount of nominal balances and decrease the domestic public debt by the same amount without affecting prices and allocations.

In Cole and Kocherlakota [5] and Ireland [10], the government has access to lump-sum taxation and inflation is the only distorting tax available. Therefore, the Friedman rule (17) is a necessary and sufficient condition for Pareto optimality. Hence, in those papers the results presented in propositions 2 and 3 are exclusively associated with the unique Pareto efficient allocation. This is not the case here. The results in question are true regardless of the optimality of the policy rule (17).

\section{Pareto efficiency}

In this section we discuss the properties and implementation of policies that lead to Pareto efficient outcomes. The first step consists in defining Pareto efficiency for the economy being considered.

Definition 2 An allocation $\chi^{*}$ is Pareto efficient if it satisfies (1) and (13) and there is no other allocation $\chi$ that satisfies these constraints and

$$
\sum_{t=0}^{\infty} \beta^{t} u\left(c_{t}^{T}, c_{1 t}^{N}, c_{2 t}^{N}, l_{t}\right)>\sum_{t=0}^{\infty} \beta^{t} u\left(c_{t}^{T *}, c_{1 t}^{N *}, c_{2 t}^{N *}, l_{t}^{*}\right) .
$$

An obvious consequence of the above definition is that an allocation $\chi^{*}$ is Pareto efficient if and only if it maximizes (4) subject to (1) and (13).

Under standard assumptions on $u$, there is a unique Pareto efficient allocation. This allocation is characterized by the following set of conditions: (1), (13) plus

$$
\begin{gathered}
u_{1}(t)=u_{2}(t) ; \\
\frac{u_{T}(t)}{u_{2}(t)}=\frac{\alpha^{N}\left(l_{t}^{T}\right)^{1-\alpha^{T}}}{\alpha^{T}\left(l_{t}^{N}\right)^{1-\alpha^{N}}} ; \\
\beta \frac{u_{T}(t+1)}{u_{T}(t)}=\frac{1}{1+i_{t+1}^{F}} ; \\
-\frac{u_{l}(t)}{u_{2}(t)}=\frac{\alpha^{N}}{\left(l_{t}^{N}\right)^{1-\alpha^{N}}} .
\end{gathered}
$$

The above equalities are first-order necessary and sufficient conditions of the problem of maximizing (4) subject to (1) and (13).

Example 1 This example illustrates the properties of Pareto efficient allocation and policy. Suppose that period preferences are given by $u=\log c^{T}+\log c_{1}^{N}+$ 
$\log c_{2}^{N}+\log (1-l)$. Foreign interest rate and preference discount factor satisfy $1+i_{t+1}^{F}=\beta^{-1}$. Technology is described by $y^{T}=\sqrt{l^{T}}$ and $y^{N}=l^{N}$. Government consumption of the tradable good satisfies $g_{t}^{T}=0$. Condition (22) implies that $c_{t}^{T}$ is constant. Simple algebra shows that conditions (1), (20), (21), (23) can be reduced to

$$
\begin{gathered}
c_{2 t}^{N}=1-l_{t}^{T}-l_{t}^{N} ; \\
2 c_{2 t}^{N}+g_{t}^{N}=l_{t}^{N} ; \\
c_{2 t}^{N}=2 c^{T} \sqrt{l_{t}^{T}} .
\end{gathered}
$$

Schmitt-Grohé and Uribe [16] studied the problem of selecting optimal monetary and fiscal policies in an one-sector small open economy. They concluded that innovations in government consumption will have no impact on the optimal levels of consumption and amount of time worked. This is not the case here. If $c_{2 t}^{N}$ were constant, both $l_{t}^{T}$ and $l_{t}^{N}$ would also be constant. That would violate the second equality above. In a multi-sector economy, efficiency requires that innovations in a non-tradable sector not to be fully smoothed out.

We now turn our attention to the characterization of Pareto efficient policies. We will show that some necessary and sufficient conditions are

$$
\tau_{t}^{N}=\tau_{t}^{T}=-\tau_{t}^{l}
$$

and

$$
\frac{1}{1+i_{t+1}^{F}}=\frac{1+\tau_{t+1}^{T}}{1+\tau_{t}^{T}} \frac{1}{1+\left(1-\delta_{t+1}^{F}\right) i_{t+1}^{F}} .
$$

The first condition is a standard uniform commodity taxation requirement. It requires consumption and leisure to be taxed at the same rate (recall that a subsidy on labor is a tax on leisure). The second constraint requires that no wedge exists between the prevailing international interest rates and the rate at which the household can borrow and lend abroad.

Proposition 4 Let $(\varphi, \chi, \zeta)$ be a competitive equilibrium for some tax system $\xi$. Then, $\chi$ is Pareto efficient if and only if $(\xi, \varphi, \chi, \zeta)$ satisfies (17), (24), (25) and $u_{1}(0)=u_{2}(0)$.

Proof. See Appendix.

Proposition 4 yields a simple way to test the Pareto efficiency of a given competitive equilibrium. However, it does not bring any insight into the issue of implementing a Pareto efficient allocation. Closing the present section, this particular problem is discussed next.

For a planner to be able to implement a Pareto efficient allocation, a regularity condition has to imposed on initial asset holdings. Namely,

$$
\frac{B_{H 0}^{F}}{\sum_{t=0}^{\infty} \beta^{t} W(t)-u_{1}(0) c_{10}^{N}-u_{2}(0) \frac{\left(1+i_{0}\right) B_{0} c_{1,0}^{N}}{M_{0}}}>0
$$


Alexandre B. Cunha

suffices to ensure that a Pareto efficient allocation can be decentralized. Essentially, that condition guarantees that even if no lump-sum revenue is available, it is possible to balance the government budget constraint with distorting taxes that satisfy the uniform taxation condition (24).

Proposition 5 Let $\chi$ be a Pareto efficient allocation. If it satisfies (26), then there exist sequences $\xi, \varphi$ and $\zeta$ such that $(\varphi, \chi, \zeta)$ is a competitive equilibrium for $\xi$.

Proof. See Appendix.

Even if some taxes are exogenous, it can still be possible to decentralize a Pareto efficient allocation. For instance, suppose that $\tau_{t}^{N}=\tau_{t}^{T}=-\tau_{t}^{l}=0$. If the government manages to raise enough tax revenues to balance its budget with the lump-sum taxes on profits, then a Pareto efficient allocation can be implemented by setting $\delta_{t}^{F}=0$.

\section{Ramsey efficiency}

This section considers situations in which a first-best Pareto efficient allocation for some reason cannot be implemented. For instance, (10) must hold in any competitive equilibrium. If tax rates on consumption are exogenous and do not satisfy $\tau_{t}^{N}=\tau_{t}^{T}$, then a competitive equilibrium allocation surely will fail to be Pareto efficient.

Following the tradition started with the seminal paper of Ramsey [15], we study the problem of selecting a best attainable allocation. However, we carry out this task under different assumptions on the ability of the Ramsey planner to select the tax rates. For instance, we look into the problem in question under the assumption that both $\tau_{t}^{N}$ and $\tau_{t}^{T}$ are selected by the Ramsey planner. Then, we study the same problem under the assumption that these two tax rates are exogenous.

Not surprisingly, we concluded that under standard assumptions on preferences, a second-best solution will display the Friedman rule $i_{t+1}=0$ as one of its features. What we did not expect is that the optimality of the Friedman rule may survive even if we further restrict the government choice of tax rates. That is, the Friedman rule may arise as a component of third or fourth-best solutions.

A standard procedure to compute the Ramsey allocation is to maximize the lifetime utility (4) subject to some implementability constraints. Regardless of which taxes the government can select, conditions (1), (12) and (13) must constrain the allocation being chosen. The remaining constraints to be considered depends on which taxes are exogenous and which are not. For instance, if both $\tau_{t}^{T}$ and $\delta_{t}^{F}$ are exogenous, then (9) must constrain the Ramsey planner's choice. On the other hand, if the planner picks both of these taxes, then that condition can be disregarded. 
The reasoning presented in the above paragraph is used throughout this section. We assume that some taxes are exogenous. Given this hypothesis, we identify which constraints the Ramsey planner faces. Then, we solve a standard maximization problem and check whether or not its solution satisfies the Friedman rule.

We now introduce an assumption on preferences usually found in the related literature. Let $h$ be a function that represents homothetic preferences on $\mathbb{R}_{+}^{3}$. We assume that the period utility function $u$ can be expressed as

$$
u\left(c^{T}, c_{1}^{N}, c_{2}^{N}, l\right)=F\left(h\left(c^{T}, c_{1}^{N}, c_{2}^{N}\right), l\right) .
$$

Most of the period utility functions found in the macroeconomic literature can be expressed as in (27).

Lemma 1 If the period utility function $u$ satisfies (27), then it satisfies the following conditions:

$$
\begin{gathered}
\frac{u_{T l}}{u_{T}}=\frac{u_{1 l}}{u_{1}}=\frac{u_{2 l}}{u_{2}}, \frac{u_{T 1}}{u_{1}}=\frac{u_{T 2}}{u_{2}} ; \\
\frac{u_{T 1}}{u_{1}} c^{T}+\sum_{j=1}^{2} \frac{u_{1 j}}{u_{1}} c_{j}^{N}+\frac{u_{1 l}}{u_{1}} l=\frac{u_{T 2}}{u_{2}} c^{T}+\sum_{j=1}^{2} \frac{u_{2 j}}{u_{2}} c_{j}^{N}+\frac{u_{2 l}}{u_{2}} l \\
\frac{u_{T T}}{u_{T}} c^{T}+\sum_{j=1}^{2} \frac{u_{T j}}{u_{T}} c_{j}^{N}+\frac{u_{T l}}{u_{T}} l=\frac{u_{T 2}}{u_{2}} c^{T}+\sum_{j=1}^{2} \frac{u_{2 j}}{u_{2}} c_{j}^{N}+\frac{u_{2 l}}{u_{2}} l .
\end{gathered}
$$

Proof. See Appendix.

The next proposition, which constitutes a standard second-best result, shows that the Friedman rule is optimal and consumption goods are taxed in a uniform fashion whenever the Ramsey planner can optimally select all but one of the distorting tax rates.

Proposition 6 Assume that u satisfies (27). If the Ramsey planner can choose at least three of the four sequences of taxes $\left\{\tau_{t}^{N}\right\}_{t=0}^{\infty},\left\{\tau_{t}^{T}\right\}_{t=0}^{\infty},\left\{\tau_{t}^{l}\right\}_{t=0}^{\infty}$ and $\left\{\delta_{t}^{F}\right\}_{t=0}^{\infty}$, as well as $\left\{\delta_{t}^{N}\right\}_{t=0}^{\infty}$ and $\left\{\delta_{t}^{T}\right\}_{t=0}^{\infty}$, then the optimal policy specifies $i_{t+1}=0$ and $\tau_{t+1}^{N}=\tau_{t+1}^{T}$ for all $t$.

Proof. This proof builds on the arguments of Chari, Christiano and Kehoe [3]. Suppose that $\left\{\tau_{t}^{l}\right\}_{t=0}^{\infty}$ is exogenous and $\left\{\tau_{t}^{N}\right\}_{t=0}^{\infty},\left\{\tau_{t}^{T}\right\}_{t=0}^{\infty}$, and $\left\{\delta_{t}^{F}\right\}_{t=0}^{\infty}$ are endogenous. Thus, given some allocation $\chi$, the Ramsey planner can pick $\left\{\tau_{t}^{N}\right\}_{t=0}^{\infty}$ so that (11) is satisfied, $\left\{\tau_{t}^{T}\right\}_{t=0}^{\infty}$ so that (10) holds and $\left\{\delta_{t}^{F}\right\}_{t=0}^{\infty}$ to satisfy (9). Thus, these constraints can be disregarded when choosing a secondbest allocation. Of course, the same is true regardless of which sequence is exogenous.

Our problem consists in selecting a best competitive equilibrium allocation. Observe that if such an allocation can be implemented by policies that satisfy 
$\delta_{t}^{N}<1$ or $\delta_{t}^{T}<1$ for some $t$, this amounts to saying that the available lump-sum tax revenues have not been fully used up. Then, the allocation in question must be Pareto efficient and the proposition is established. So, in what follows, we will assume that $\delta_{t}^{N}=\delta_{t}^{T}=1$.

Plug the above equalities into (12). This procedure yields

$$
\begin{gathered}
\sum_{t=0}^{\infty} \beta^{t} W(t)=u_{1}(0) c_{1,0}^{N}+ \\
u_{2}(0)\left[\frac{\left(1+i_{0}\right) B_{0}}{\left(1+\tau_{0}^{N}\right) p_{0}^{N}}+\frac{M_{0}}{\left(1+\tau_{0}^{N}\right) p_{0}^{N}}-c_{1,0}^{N}\right]+u_{T}(0) \frac{\left[1+\left(1-\delta_{0}^{F}\right) i_{0}^{F}\right] B_{H 0}^{F}}{1+\tau_{0}^{T}} .
\end{gathered}
$$

Consider the problem of maximizing (4) subject to (1), (31) and (13). If it were not for constraints (16) and (15), the solution to this problem would be a best competitive equilibrium allocation. The argument used in the proof of Proposition 5 establishes that the solution will satisfy (16). So, if the solution respects (15), such a solution will yield the highest attainable utility level. This turns out to be exactly the case.

Let $\Gamma$ and $\beta^{t} \gamma_{t}^{N}$ be Lagrange multipliers for, respectively, (31) and the resource constraint for the non-tradable sector. For $t \geq 1$, the respective first-order conditions for $c_{1 t}^{N}$ and $c_{2 t}^{N}$ are

$$
\frac{\gamma_{t}^{N}}{u_{1}(t)}=1+\Gamma+\Gamma\left[\frac{u_{T 1}(t)}{u_{1}(t)} c_{t}^{T}+\frac{u_{11}(t)}{u_{1}(t)} c_{1 t}^{N}+\frac{u_{12}(t)}{u_{1}(t)} c_{2 t}^{N}+\frac{u_{1 l}(t)}{u_{1}(t)} l_{t}\right]
$$

and

$$
\frac{\gamma_{t}^{N}}{u_{2}(t)}=1+\Gamma+\Gamma\left[\frac{u_{T 2}(t)}{u_{2}(t)} c_{t}^{T}+\frac{u_{12}(t)}{u_{2}(t)} c_{1 t}^{N}+\frac{u_{22}(t)}{u_{2}(t)} c_{2 t}^{N}+\frac{u_{2 l}(t)}{u_{2}(t)} l_{t}\right] .
$$

Apply Lemma 1 to conclude that $u_{1}(t)=u_{2}(t)$, which implies $i_{t}=0$.

To establish the second equality, let $\beta^{t} \gamma_{t}^{T}$ be the Lagrange multiplier for the tradable sector resource constraint. The first order condition for $c_{t}^{T}$ is

$$
\frac{\gamma_{t}^{T}}{u_{T}(t)}=1+\Gamma+\Gamma\left[\frac{u_{T T}(t)}{u_{T}(t)} c_{t}^{T}+\frac{u_{T 1}(t)}{u_{T}(t)} c_{1 t}^{N}+\frac{u_{T 2}(t)}{u_{T}(t)} c_{2 t}^{N}+\frac{u_{T l}(t)}{u_{T}(t)} l_{t}\right] .
$$

Another appeal to Lemma 1 yields

$$
\frac{u_{T}(t)}{u_{2}(t)}=\frac{\gamma_{t}^{T}}{\gamma_{t}^{N}}
$$

On the other hand, the first order conditions for $l_{t}^{T}$ and $l_{t}^{N}$ imply

$$
\frac{\gamma_{t}^{T}}{\gamma_{t}^{N}}=\frac{\alpha^{N}\left(l_{t}^{T}\right)^{1-\alpha^{T}}}{\alpha^{T}\left(l_{t}^{N}\right)^{1-\alpha^{N}}}
$$

From the last two equalities, we have (21). Hence, (10) implies $\tau_{t}^{N}=\tau_{t}^{T}$. 
The proof of the forthcoming Proposition 8 makes clear that the endogeneity of $\left\{\delta_{t}^{N}\right\}_{t=0}^{\infty}$ and $\left\{\delta_{t}^{T}\right\}_{t=0}^{\infty}$ is not relevant for the optimality of the Friedman rule. However, that assumption cannot be dispensed with when proving that $\tau_{t+1}^{N}=\tau_{t+1}^{T}$. For instance, if $\left\{\tau_{t}^{l}\right\}_{t=0}^{\infty},\left\{\delta_{t}^{N}\right\}_{t=0}^{\infty}$ and $\left\{\delta_{t}^{T}\right\}_{t=0}^{\infty}$ were exogenous, the equivalent of $(32)$ would be

$$
\frac{\gamma_{t}^{T}}{\gamma_{t}^{N}}=\frac{\alpha^{N}\left(l_{t}^{T}\right)^{1-\alpha^{T}}+\Gamma \frac{u_{l}(t)}{1-\tau_{t}^{l}}\left(1-\delta_{t}^{T}\right) \frac{1-\alpha^{T}}{\alpha^{T}}}{\alpha^{T}\left(l_{t}^{N}\right)^{1-\alpha^{N}}+\Gamma \frac{u_{l}(t)}{1-\tau_{t}^{l}}\left(1-\delta_{t}^{N}\right) \frac{1-\alpha^{N}}{\alpha^{N}}} .
$$

Hence, unless very particular restrictions were placed on $\left\{\delta_{t}^{N}\right\}_{t=0}^{\infty}$ and $\left\{\delta_{t}^{T}\right\}_{t=0}^{\infty}$, we would have $\tau_{t}^{N} \neq \tau_{t}^{T}$. In similar fashion, the endogeneity of $\left\{\delta_{t}^{N}\right\}_{t=0}^{\infty}$ and $\left\{\delta_{t}^{T}\right\}_{t=0}^{\infty}$ cannot be dispensed with when proving that the Ramsey planner will not distort the margin (22), as we do in the next proposition. Similar remarks apply to the all propositions and corollaries of this section.

Carlstrom and Fuerst [1] argued that in an open economy, the existence of a given international interest rate will impact the behavior of domestic agents in a way that the Friedman rule may fail to be optimal. A possible way to circumvent such a constraint is to tax the income on foreign assets. This possibility is encompassed in Proposition 6. However, the same proposition also shows that even if $\delta_{t}^{F}=0$, the Friedman rule may still be optimal. All that is needed is the Ramsey planner to have access to a sufficiently large set of alternative tax instruments.

We established in Proposition 6 that a second-best policy induces an allocation that displays, at least for $t \geq 1$, the properties (20) and (21) of a Pareto efficient allocation. Some the two remaining margins (23) and (22) may fail to hold in a second best solution. We next show that, under an additional assumption on the period utility function $u$, a second best allocation satisfies condition (22). Of course, this last condition is satisfied if and only if (25) holds.

Recall that (27) constitutes a separability condition on consumption levels and labor. A more restrictive hypothesis consists in assuming that $u$ can be expressed as

$$
u\left(c^{T}, c_{1}^{N}, c_{2}^{N}, l\right)=h\left(c^{T}, c_{1}^{N}, c_{2}^{N}\right)+G(l),
$$

where $h$ again represents homothetic preferences. Period preferences in that class are often adopted in small open economy models.

Proposition 7 Assume that u satisfies (33). Under the remaining assumptions of Proposition 6, the optimal policy satisfies (25) for all t.

Proof. Again, if $\delta_{t}^{N}<1$ or $\delta_{t}^{T}<1$ there is nothing to show. So, we assume that $\delta_{t}^{N}=\delta_{t}^{T}=1$. Let $\gamma_{t}^{T}$ and $\Gamma$ have the previously defined meanings. Write the first order condition for $c_{t}^{T}$ as

$$
\gamma_{t}^{T}=u_{T}(t)\left[1+\Gamma \frac{W_{T}(t)}{u_{T}(t)}\right]
$$


where $W_{T}(t)$ denotes the partial derivative $\frac{\partial W}{\partial c^{T}}$ evaluated at $\left(c_{t}^{T}, c_{1 t}^{N}, c_{2 t}^{N}, l_{t}\right)$. On the other hand, the first order conditions for $x_{t}$ and $x_{t+1}$ imply

$$
\beta \frac{\gamma_{t+1}^{T}}{\gamma_{t}^{T}}=\frac{1}{1+i_{t+1}^{F}}
$$

Hence, we combine the last two equalities to obtain

$$
\frac{1}{1+i_{t+1}^{F}}=\beta \frac{u_{T}(t+1)}{u_{T}(t)} \frac{\left[1+\Gamma \frac{W_{T}(t+1)}{u_{T}(t+1)}\right]}{\left[1+\Gamma \frac{W_{T}(t)}{u_{T}(t)}\right]} .
$$

If $h\left(c^{T}, c_{1}^{N}, c_{2}^{N}\right)=\theta^{T} \log c^{T}+\theta_{1} \log c_{1}^{N}+\theta_{2} \log c_{2}^{N}$, then $W_{T}(t)=0$. Thus, (8) and (34) imply (25). For other types of homothetic preferences, $h$ must be homogenous of some degree $k$. Then,

$$
\begin{gathered}
W\left(c^{T}, c_{1}^{N}, c_{2}^{N}\right)=\frac{\partial h}{\partial c^{T}}\left(c^{T}, c_{1}^{N}, c_{2}^{N}\right) c^{T}+\sum_{n=1}^{2} \frac{\partial h}{\partial c_{i}^{N}}\left(c^{T}, c_{1}^{N}, c_{2}^{N}\right) c_{i}^{N}+G^{\prime}(l) l \Rightarrow \\
W\left(c^{T}, c_{1}^{N}, c_{2}^{N}\right)=k h\left(c^{T}, c_{1}^{N}, c_{2}^{N}\right)+G^{\prime}(l) l \Rightarrow W_{T}(t)=k u_{T}(t)
\end{gathered}
$$

and (8) and (34) again lead to (25).

The hypothesis on the period utility function is essential for the above result. For instance, if

$$
u\left(c^{T}, c_{1}^{N}, c_{2}^{N}, l\right)=\frac{\left[\left(c^{T}\right)^{\theta^{T}}\left(c_{1}^{N}\right)^{\theta_{1}}\left(c_{2}^{N}\right)^{\theta_{2}}(1-l)^{\theta^{l}}\right]^{1-\sigma}}{1-\sigma},
$$

then the ratio $\frac{W_{T}(t)}{u_{T}(t)}$ will depend on $l_{t}$. Since this last variable is not necessarily constant in the Ramsey solution, the Ramsey policy generally will not respect (25).

The separability assumption on (27) ensures that the ratios $\frac{u_{2}(t)}{u_{1}(t)}$ and $\frac{u_{T}(t)}{u_{2}(t)}$ depend only on $\left(c_{t}^{T}, c_{1 t}^{N}, c_{2 t}^{N}\right)$. This explains why the Ramsey solution respects (20) and (21). Under (27), $\frac{u_{T}(t+1)}{u_{T}(t)}$ does depend on $t$ and $t+1$ consumption levels and may depend on $l_{t}$ and $l_{t+1}$. For this reason the Ramsey solution may fail to respect (22). Under the stronger separability assumption (33), the ratio $\frac{u_{T}(t+1)}{u_{T}(t)}$ does not depend on either $l_{t}$ or $l_{t+1}$. Therefore, in such a context the Ramsey planner does not distort the margin (22).

We know compare our results on the taxation of foreign assets income to some of those on physical capital income Chari and Kehoe [4] discussed. Those authors studied the problem of optimal taxation of capital income in a onesector closed economy. They found out that in a steady state, the optimal tax rate on capital income is zero. We can obtain an equivalent result here. Indeed, in a steady state the ratio $\frac{W_{T}}{u_{T}}$ is constant. Hence, (34) imply that the 
The Optimality of the Friedman Rule

Ramsey planner does not distort the margin (22). Note that this conclusion does not depend on separability assumptions like (27) or (33). Chari and Kehoe also showed if period preferences in their model satisfied a separability condition similar to (33), the optimal tax on capital income was zero. The analogy between this result and Proposition 7 is obvious.

We showed in Proposition 6 that second best policies call for a uniform taxation of consumption goods. Suppose now that the Ramsey planner cannot select the tax rates on consumption, but these exogenous taxes satisfy the uniform taxation property $\tau_{t}^{N}=\tau_{t}^{T}$ for all $t$. The Friedman rule turns out to be optimal.

Corollary 1 Assume that $u$ satisfies (27). If consumption tax rates are exogenous and satisfy $\tau_{t}^{N}=\tau_{t}^{T}$ and the Ramsey planner can select $\left\{\tau_{t}^{l}\right\}_{t=0}^{\infty},\left\{\delta_{t}^{F}\right\}_{t=0}^{\infty}$, $\left\{\delta_{t}^{N}\right\}_{t=0}^{\infty}$ and $\left\{\delta_{t}^{T}\right\}_{t=0}^{\infty}$, then the optimal policy specifies $i_{t+1}=0$ for all $t$.

Proof. See Appendix.

As we showed in Proposition 6, the second best policy satisfy $\tau_{t+1}^{N}=\tau_{t+1}^{T}$. Hence, one could wrongly assume that the condition $\tau_{t}^{N}=\tau_{t}^{T}$ we assumed in the previous proposition does not further constraint the Ramsey planner. However, this is not necessarily true. Observe that the implementability constraint (12) depends on the tax rates $\tau_{0}^{N}$ and $\tau_{0}^{T}$, which can be both selected by the Ramsey planner in Proposition 6. Consequently, unless $\tau_{0}^{N}$ and $\tau_{0}^{T}$ are exogenously set at their second best levels, the allocation the Ramsey planner induces under the assumptions of Corollary 1 is not the same one induced in Proposition 6 .

Clearly, the Corollary 1 encompasses the case in which $\tau_{t}^{N}=\tau_{t}^{T}=0$. Schmitt-Grohé and Uribe [16] studied the optimality of the Friedman rule in a cash-credit one-sector small open economy. They concluded that if the Ramsey planner does not have access to consumption taxes (i.e., such taxes are equal to zero) but has access to labor income taxes, the Friedman rule is not optimal. Our conclusion is different from theirs because we allowed the Ramsey planner to pick $\left\{\delta_{t}^{F}\right\}_{t=0}^{\infty}$ in an optimal fashion.

The assumption that $\tau_{t}^{N}=\tau_{t}^{T}$ is essential in Corollary 1 . Had it not been imposed, the Friedman rule would not be optimal. The next example discusses this case.

Remark 1 Consider now the situation in which tax rates satisfy all hypotheses of Corollary 1, except that now $\tau_{t}^{N} \neq \tau_{t}^{T}$. This non-uniform taxation of consumption goods will prevent the Friedman Rule from being optimal. Further details are provided in the Appendix.

The reasoning underlying Corollary 1 allow us to conclude that the Friedman rule is optimal under more restrictive assumptions on the availability of distorting taxes, provided that we replace condition (27) by (33). 
Alexandre B. Cunha

Corollary 2 Assume that $u$ satisfies (33). If the tax rates on consumption and foreign assets income are exogenous and satisfy $\tau_{t}^{N}=\tau_{t}^{T}$ and (25) and the Ramsey planner can select $\left\{\tau_{t}^{l}\right\}_{t=0}^{\infty},\left\{\delta_{t}^{N}\right\}_{t=0}^{\infty}$ and $\left\{\delta_{t}^{T}\right\}_{t=0}^{\infty}$, then the optimal policy specifies $i_{t+1}=0$ for all $t$.

Proof. See Appendix.

We next establish a very strong result. Namely, the endogeneity of the tax rate on the consumption of non-tradable goods is a sufficient condition for the optimality of the Friedman rule.

Proposition 8 Assume that u satisfies (27). If the Ramsey planner can select $\left\{\tau_{t}^{N}\right\}_{t=0}^{\infty}$, then the optimal policy specifies $i_{t+1}=0$ for all $t$.

Proof. For a while, assume that all taxes but $\left\{\tau_{t}^{N}\right\}_{t=0}^{\infty}$ are exogenous. Combine (10) and (11) to obtain

$$
-\frac{u_{l}(t)}{u_{T}(t)}=\frac{1-\tau_{t}^{l}}{1+\tau_{t}^{T}} \frac{\alpha^{T}}{\left(l_{t}^{T}\right)^{1-\alpha^{T}}}
$$

or, equivalently,

$$
\left(1-\tau_{t}^{l}\right) \alpha^{T} u_{T}(t)=-\left(1+\tau_{t}^{T}\right)\left(l_{t}^{T}\right)^{1-\alpha^{T}} u_{l}(t) .
$$

Consider the problem of maximizing (4) subject to (1), (9), (36), (12), and (13). Note that it is possible to decentralize the solution of this problem by picking $\tau_{t}^{N}$ to satisfy (10). Let $\beta^{t} \gamma_{t}^{F}$ and $\beta^{t} \eta_{t}$ be Lagrange multipliers for, respectively, (9) and (36). The remaining variables have the previously defined meanings. The first-order conditions with respect to $c_{1 t}^{N}$ and $c_{2 t}^{N}$ yield

$$
\begin{gathered}
\frac{\gamma_{t}^{N}}{u_{1}(t)}=(1+\Gamma)+\Gamma\left\{\frac{u_{T 1}(t)}{u_{1}(t)} c_{t}^{T}+\frac{u_{11}(t)}{u_{1}(t)} c_{1 t}^{N}+\frac{u_{12}(t)}{u_{1}(t)} c_{2 t}^{N}+\frac{u_{1 l}(t)}{u_{1}(t)} l_{t}+\right. \\
\left.\frac{u_{1 l}(t)}{u_{1}(t)\left(1-\tau_{t}^{l}\right)}\left[\left(1-\delta_{t}^{T}\right) \frac{1-\alpha^{T}}{\alpha^{T}} l_{t}^{T}+\left(1-\delta_{t}^{N}\right) \frac{1-\alpha^{N}}{\alpha^{N}} l_{t}^{N}\right]\right\}+\gamma_{t}^{F} \frac{u_{T 1}(t)}{u_{1}(t)}+ \\
\eta_{t}\left[\left(1-\tau_{t}^{l}\right) \alpha^{T} \frac{u_{T 1}(t)}{u_{1}(t)}+\left(1+\tau_{t}^{T}\right)\left(l_{t}^{T}\right)^{1-\alpha^{T}} \frac{u_{1 l}(t)}{u_{1}(t)}\right]
\end{gathered}
$$

and

$$
\begin{gathered}
\frac{\gamma_{t}^{N}}{u_{2}(t)}=(1+\Gamma)+\Gamma\left\{\frac{u_{T 2}(t)}{u_{2}(t)} c_{t}^{T}+\frac{u_{12}(t)}{u_{2}(t)} c_{1 t}^{N}+\frac{u_{22}(t)}{u_{2}(t)} c_{2 t}^{N}+\frac{u_{2 l}(t)}{u_{2}(t)} l_{t}+\right. \\
\left.\frac{u_{2 l}(t)}{u_{2}(t)\left(1-\tau_{t}^{l}\right)}\left[\left(1-\delta_{t}^{T}\right) \frac{1-\alpha^{T}}{\alpha^{T}} l_{t}^{T}+\left(1-\delta_{t}^{N}\right) \frac{1-\alpha^{N}}{\alpha^{N}} l_{t}^{N}\right]\right\}+\gamma_{t}^{F} \frac{u_{T 2}(t)}{u_{2}(t)}+ \\
\eta_{t}\left[\left(1-\tau_{t}^{l}\right) \alpha^{T} \frac{u_{T 2}(t)}{u_{2}(t)}+\left(1+\tau_{t}^{T}\right)\left(l_{t}^{T}\right)^{1-\alpha^{T}} \frac{u_{2 l}(t)}{u_{2}(t)}\right] .
\end{gathered}
$$


The Optimality of the Friedman Rule

Again, the equalities in Lemma 1 lead to the desired result. Finally, if the Ramsey planner can choose other taxes besides $\left\{\tau_{t}^{N}\right\}_{t=0}^{\infty}$, it suffices to drop the proper constraints from the maximization problem and use exactly the same reasoning.

The intuition for the above result is as follows. The tax on the consumption of non-tradables distorts several margins. But it does not distort the margin between $c_{1}^{N}$ and $c_{2}^{N}$. A positive nominal interest rate distorts this last margin plus all the others distorted by $\tau^{N}$. Thus, it is optimal not to use the nominal interest rate as a source of revenue for the government.

Let us juxtapose Proposition 8 to the non optimality of the Friedman rule in Cavalcanti and Villamil [2]. These authors considered a model with a formal and an informal (i.e., underground) sectors. The only possible way the Ramsey planner could exact tax revenue from the informal sector was through inflation. In view of Proposition 8, we conjecture that the inability of the Ramsey planner to tax the informal sector without using inflation is necessary condition for the non optimality of the Friedman rule in their model.

We have assumed that the Ramsey planner can implement only linear taxation schemes. Of course, not only those tax schemes can implement the optimal allocations. We have also assumed that exogenous taxes are linear. We could easily relax that assumption and Proposition 8 would still hold. For instance, suppose that the date $t$ tax rate on labor income is an exogenous function of $l_{t}$. Exactly the same proof could be applied to establish the optimality of the Friedman rule. Indeed, all that is required in our reasoning is that the exogenous tax rates do not depend on $\left\{c_{1 t}^{N}\right\}_{t=0}^{\infty}$ or $\left\{c_{2 t}^{N}\right\}_{t=0}^{\infty}$.

It follows directly from Proposition 8 that if the Friedman rule is not optimal, then $\left\{\tau_{t}^{N}\right\}_{t=0}^{\infty}$ is exogenous. On the other hand, Proposition 6 shows that the Friedman rule may be optimal even if $\left\{\tau_{t}^{N}\right\}_{t=0}^{\infty}$ is exogenous. Thus, $\left\{\tau_{t}^{N}\right\}_{t=0}^{\infty}$ being endogenous is a sufficient, but not necessary, condition for the optimality of the Friedman rule. However, as Remark 1 illustrates, if $\left\{\tau_{t}^{N}\right\}_{t=0}^{\infty}$ and another distorting tax sequence is exogenous, the Friedman rule may fail to be optimal.

We can obtain some additional insights by comparing Corollary 1 and Proposition 8. Consider the latter result. Suppose that $\tau_{t}^{T}=0$ and that to balance the government budget, the optimal value of $\tau_{t}^{N}$ is positive at every period. Since a competitive equilibrium must respect (10), the optimal policy surely will distort the margin (21). However, as pointed out in the previous example, the condition $\tau_{t}^{N}=\tau_{t}^{T}$, which ensures that (21) is satisfied, is essential in Corollary 1 . Hence, it is not possible to associate the optimality of the Friedman rule with uniform or non-uniform taxation of the consumption goods without knowing which taxes are selected by the Ramsey planner.

\section{Conclusion}

The Friedman rule (i.e., zero nominal interest rates) has been the focus of a large body of literature on optimal monetary and fiscal policy. In this paper 
Alexandre B. Cunha

we investigated the relation between the optimality of the Friedman rule and the number of distorting tax instruments available to a benevolent planner. We carried out the study in a two-sector (tradable and non-tradable goods) small open economy framework. We introduced money by assuming that a fraction of people's purchases of non-tradables has to be paid cash.

Most of the previous studies on the optimality of the Friedman rule adopted one-sector models. In such models, the number of conceivable distorting tax instruments is small. Usually the only possible distorting taxes are on labor income and on consumption. In a more sophisticated model, one can devise many more taxes. It turns out that the optimality of the Friedman rule critically depends on the set of distorting taxes that the planner can select from.

We showed that the Friedman rule is a necessary condition for Pareto efficiency. Additionally, for some values of initial cash, public debt and foreign asset holdings, it is possible to support a Pareto efficient allocation as a competitive equilibrium, provided that all conceivable distorting tax rates are available to the planner.

We considered several situations in which not all conceivable distorting taxes can be selected in an efficient manner. A sufficient condition for the optimality of the Friedman rule is that the Ramsey planner can choose the tax rate on the consumption of the non-tradable good. However, there are some circumstances in which that tax rate is exogenous and the Friedman rule is still optimal and there are some in which it fails to be optimal. Thus, the optimality of Friedman's prescription does depend on the set of distorting taxes that can be selected by the planner.

\section{Appendix}

\subsection{Households' first-order conditions}

If $M_{0}$ is positive, the first-order necessary and sufficient conditions for a typical household are

$$
\begin{gathered}
\beta^{t} u_{T}(t)=\lambda_{t}\left(1+\tau_{t}^{T}\right) E_{t} ; \\
\beta^{t} u_{1}(t)=\left(\lambda_{t}+\mu_{t}\right)\left(1+\tau_{t}^{N}\right) p_{t}^{N} ; \\
\beta^{t} u_{2}(t)=\lambda_{t}\left(1+\tau_{t}^{N}\right) p_{t}^{N} ; \\
-\beta^{t} u_{l}(t)=\lambda_{t}\left(1-\tau_{t}^{l}\right) w_{t} ; \\
\lambda_{t}=\lambda_{t+1}+\mu_{t+1} ; \\
\lambda_{t}=\lambda_{t+1}\left(1+i_{t+1}\right) ; \\
M_{t} \geq\left(1+\tau_{t}^{N}\right) p_{t}^{N} c_{1 t}^{N} \& \mu_{t}\left[M_{t}-\left(1+\tau_{t}^{N}\right) p_{t}^{N} c_{1 t}^{N}\right]=0 ; \\
\left(1+\tau_{t}^{T}\right) E_{t} c_{t}^{T}+\left(1+\tau_{t}^{N}\right) p_{t}^{N}\left(c_{1 t}^{N}+c_{2 t}^{N}\right)+ \\
\lambda_{t+1}+B_{t+1}+E_{t} B_{H t+1}^{F}=\left(1-\tau_{t}^{l}\right) w_{t} l_{t}+M_{t}+
\end{gathered}
$$


The Optimality of the Friedman Rule

$$
\begin{gathered}
\left(1+i_{t}\right) B_{t}+E_{t}\left[1+\left(1-\delta_{t}^{F}\right) i_{t}^{F}\right] B_{H t}^{F}+\left(1-\delta_{t}^{T}\right) \psi_{t}^{T}+\left(1-\delta_{t}^{N}\right) \psi_{t}^{N} \\
\lim _{t \rightarrow \infty} \lambda_{t} M_{t+1}=\lim _{t \rightarrow \infty} \lambda_{t} B_{t+1}=\lim _{t \rightarrow \infty} \lambda_{t} E_{t} B_{H t+1}^{F}=0 ; \\
c_{t}^{T}, c_{1 t}^{N}, c_{2 t}^{N}, l_{t}, M_{t}, \lambda_{t}, \mu_{t} \geq 0, l_{t} \leq 1 ;
\end{gathered}
$$

where $\lambda_{t}$ and $\mu_{t}$ are Lagrange multipliers for, respectively, budget and cash-inadvance constraints. The notation $u_{T}(t), u_{1}(t), u_{2}(t)$ and $u_{l}(t)$ was introduced on page 7 .

\subsection{Proofs}

Proof of Proposition 1: For the 'if part', suppose that $(\varphi, \chi, \zeta)$ is a competitive equilibrium. We need to show that (1) and (9)-(16) hold. Constraint (1) is trivially satisfied.

We will now show that (9) holds. Forward (37) by one period and divide it by itself. Then, combine the resulting equation with (43). This yields (8), from which (9) can be trivially obtained.

To obtain (10), divide (37) by (39) and combine the resulting equation with firms' first-order conditions. For (11), divide (40) by (39) and again combine the resulting equation with firms' first-order conditions..

Consider now (12). Multiplying (45) by $\lambda_{t}$, using (37)-(44) and the equalities $\psi_{t}^{T}=\frac{1-\alpha^{T}}{\alpha^{T}} w_{t} l_{t}^{T}$ and $\psi_{t}^{N}=\frac{1-\alpha^{N}}{\alpha^{N}} w_{t} l_{t}^{N}$ one obtains

$$
\begin{gathered}
\beta^{t} W(t)+\left(\lambda_{t+1}+\mu_{t+1}\right) M_{t+1}+\lambda_{t} B_{t+1}+ \\
\lambda_{t} E_{t} B_{H t+1}^{F}=\left(\lambda_{t}+\mu_{t}\right) M_{t}+\lambda_{t}\left(1+i_{t}\right) B_{t}+\lambda_{t} E_{t}\left[1+\left(1-\delta_{t}^{F}\right) i_{t}^{F}\right] B_{H t}^{F}- \\
\frac{\beta^{t} u_{l}(t)}{\left(1-\tau_{t}^{l}\right)}\left[\left(1-\delta_{t}^{T}\right) \frac{1-\alpha^{T}}{\alpha^{T}} l_{t}^{T}+\left(1-\delta_{t}^{N}\right) \frac{1-\alpha^{N}}{\alpha^{N}} l_{t}^{N}\right] .
\end{gathered}
$$

Summing from date 0 to some date $k$ and using (42) and (43) to cancel the identical terms out, one gets

$$
\begin{gathered}
\sum_{t=0}^{k} \beta^{t}\left\{W(t)+\frac{u_{l}(t)}{\left(1-\tau_{t}^{l}\right)}\left[\left(1-\delta_{t}^{T}\right) \frac{1-\alpha^{T}}{\alpha^{T}} l_{t}^{T}+\left(1-\delta_{t}^{N}\right) \frac{1-\alpha^{N}}{\alpha^{N}} l_{t}^{N}\right]\right\}+ \\
\lambda_{k} M_{k+1}+\lambda_{k} B_{k+1}+\lambda_{k} E_{k} B_{H k+1}^{F}= \\
\mu_{0} M_{0}+\lambda_{0}\left\{M_{0}+\left(1+i_{0}\right) B_{0}+E_{0}\left[1+\left(1-\delta_{0}^{F}\right) i_{0}^{F}\right] B_{H 0}^{F}\right\} .
\end{gathered}
$$

But $\mu_{0} M_{0}=\mu_{0}\left(1+\tau_{0}^{N}\right) p_{0}^{N} c_{1,0}^{N}=u_{1}(0) c_{10}^{N}-\lambda_{0}\left(1+\tau_{0}^{N}\right) p_{0}^{N} c_{1,0}^{N}$. Plug this last equality into (48). Then, use the fact that $\lambda_{0}=\frac{u_{T}(0)}{\left(1+\tau_{0}^{T}\right) E_{0}}=\frac{u_{2}(0)}{\left(1+\tau_{0}^{N}\right) p_{0}^{N}}$ to eliminate $\lambda_{0}$ from (48). Make $k \rightarrow \infty$ and use the transversality conditions in (46) to obtain (12). 
Equation (7) has to hold in a competitive equilibrium. Divide it by the factor $\prod_{s=1}^{t}\left(1+i^{F}\right)$. Then, sum from date 0 to some date $k$ to obtain

$$
\sum_{t=0}^{k} \frac{x_{t}}{\prod_{s=1}^{t}\left(1+i_{s}^{F}\right)}+\left(1+i_{0}^{F}\right)\left(B_{H 0}^{F}+B_{G 0}^{F}\right)=\frac{B_{H k+1}^{F}+B_{G k+1}^{F}}{\prod_{s=1}^{k}\left(1+i_{s}^{F}\right)} .
$$

Recall that both $B_{H t}^{F}$ and $B_{G t}^{F}$ are bounded and $i_{t}^{F}$ belongs to a finite set of positive numbers. Thus, as $k \rightarrow \infty$, the right hand side of (49) vanishes and (13) holds.

Constraint (14) is obviously satisfied. Concerning (15), divide (38) by (39) to obtain $\frac{u_{1}(t)}{u_{2}(t)}=1+\frac{\mu_{t}}{\lambda_{t}} \geq 1$.

We conclude the 'if part' of the proof by showing that (16) is satisfied. From (38), (41), (44) and (46),

$$
\lambda_{t-1} M_{t}=\left(\lambda_{t}+\mu_{t}\right) M_{t}=\frac{\beta^{t} u_{1}(t) M_{t}}{\left(1+\tau_{t}^{N}\right) p_{t}^{N}} \geq \frac{\beta^{t} u_{1}(t) c_{1 t}^{N}}{\left(1+\tau_{t}^{N}\right)} \geq 0 .
$$

Now make $t \rightarrow \infty$ and apply (46) to obtain (16).

For the 'only if part', take an initial price $p_{0}^{N}>0$ and an object $\chi$ satisfying (1) and (9)-(16). We must show that there exist sequences $\varphi$ and $\zeta$ such that $(\varphi, \chi, \zeta)$ satisfies all conditions of a competitive equilibrium.

Recall that $p_{0}^{N}$ is given. Thus, it is possible to define the sequence $\left\{p_{t}^{N}\right\}_{t=1}^{\infty}$ recursively. Set those prices according to the kernel

$$
p_{t+1}^{N}=p_{t}^{N} \beta \frac{1+\tau_{t}^{N}}{1+\tau_{t+1}^{N}} \frac{u_{1}(t+1)}{u_{2}(t)} .
$$

Set $\lambda_{t}$ as in (39), $\mu_{t}$ as in (38), $E_{t}$ as in (37), $i_{t}$ as in (42) and $w_{t}$ as in (40). Define cash holdings as $M_{t}=\left(1+\tau_{t}^{N}\right) p_{t}^{N} c_{1 t}^{N}$. Let $B_{H t+1}^{F}=0$. Define $B_{1}$ to balance household's budget constraint at date 1 . The entire sequence $\left\{B_{t+1}\right\}_{t=0}^{\infty}$ is constructed in this recursive way, while $\left\{B_{G t+1}^{F}\right\}_{t=0}^{\infty}$ is defined recursively to balance the budget constraint of the government.

It remains to show that the proposed $(\varphi, \chi, \zeta)$ is a competitive equilibrium. Item (iii) of definition 1 is clearly satisfied. For item (i) it is enough to prove that (37)-(47) are satisfied. The variables were defined so that (37)-(40) hold. Concerning (41), (51) implies that

$$
\frac{\beta^{t} u_{2}(t)}{\left(1+\tau_{t}^{N}\right) p_{t}^{N}}=\frac{\beta^{t+1} u_{1}(t+1)}{\left(1+\tau_{t+1}^{N}\right) p_{t+1}^{N}}
$$

This last equality, combined with (38) and (39), yields (41). The sequence $\left\{i_{t+1}\right\}_{t=0}^{\infty}$ was defined in such a way that (42) is satisfied. Observe that (9) implies (8). Combine this last equation with (37) to obtain (43). Money balances were defined so that (44) holds, while the definition of $\left\{B_{t+1}\right\}_{t=0}^{\infty}$ ensures that (45) is satisfied. The last transversality condition in (46) is trivially satisfied. To verify that the other two also hold, observe that (48) can be obtained exactly as 
The Optimality of the Friedman Rule

in the first part of the proof. Plus, (12) ensures that the series in (48) converges in $\mathbb{R}$. So, making $k \rightarrow \infty$, one concludes that $\lambda_{k} M_{k+1}+\lambda_{k} B_{k+1} \rightarrow 0$. Thus, it remains to show that either $\lambda_{k} M_{k+1}$ or $\lambda_{k} B_{k+1}$ goes to zero. Observe that (50) holds as an equality. So, (16) ensures that $\lambda_{k} M_{k+1} \rightarrow 0$. With the exception of $\mu_{t} \geq 0$, all inequalities in (47) are trivially true. To show that $\mu_{t} \geq 0$, divide (38) by (39) and use (15).

To finish the 'only if part', it remains to show that each firm is maximizing its respective date $t$ profit. Combine (39), (40) and (11) to conclude that $w_{t}=$ $p_{t}^{N} \alpha^{N}\left(l_{t}^{N}\right)^{\alpha^{N}-1}$. Finally, combine this last equality with (37), (39) and (10) to obtain $w_{t}=E_{t} \alpha^{T}\left(l_{t}^{T}\right)^{\alpha^{T}-1}$.

Proof of Proposition 2: Let $(\varphi, \chi, \zeta)$ be a competitive equilibrium that satisfies (17). This equation and (42) imply $\lambda_{t}=\lambda_{t+1}$. So, (46) implies (18). First-order conditions (38), (39) and (41) yield (51). Therefore,

$$
M_{t} \geq p_{t}^{N}\left(1+\tau_{t}^{N}\right) c_{1 t}^{N}=p_{0}^{N}\left(1+\tau_{0}^{N}\right) \beta^{t}\left[\prod_{s=1}^{t} \frac{u_{1}(s)}{u_{2}(s-1)}\right] c_{1 t}^{N} .
$$

Use the fact that $u_{1}(t+1)=u_{2}(t+1)$ to obtain

$$
\frac{M_{t}}{\beta^{t}} \geq \frac{p_{0}^{N}\left(1+\tau_{0}^{N}\right)}{u_{2}(0)} u_{1}(t) c_{1 t}^{N} .
$$

Thus, to obtain (19), it remains to show that $u_{1}(t) c_{1 t}^{N}$ is bounded away from zero. Inada conditions imply that there exists some $\varepsilon>0$ such that $c_{1 t}^{N}>\varepsilon$. Additionally, the same is true for $c_{t}^{T}, c_{2 t}^{N}$ and $1-l_{t}$. The balance-of-payments equation (7) and the boundedness of the foreign assets imply that $x_{t}$ is bounded. So, $c_{t}^{T}, c_{1 t}^{N}$ and $c_{2 t}^{N}$ are bounded above. Hence, $\left(c_{t}^{T}, c_{1 t}^{N}, c_{2 t}^{N}\right)$ lies in some compact cube in $\mathbb{R}_{++}^{3}$ and $l_{t}$ is bounded away from 1 . Since $u_{1}$ is continuous and positive, it attains a positive minimum $u_{1}^{\min }$. Therefore,

$$
\frac{M_{t}}{\beta^{t}} \geq \frac{p_{0}^{N}\left(1+\tau_{0}^{N}\right)}{u_{2}(0)} u_{1}^{\min } \varepsilon>0,
$$

from which (19) follows directly.

Proof of Proposition 3: Let $(\varphi, \chi, \zeta)$ be a competitive equilibrium that satisfies (17). Let $\left\{M_{t+1}^{\prime}\right\}_{t=0}^{\infty}$ be any sequence satisfying $M_{t+1}^{\prime} \geq M_{t+1}$ and (18). Define $B_{t+1}^{\prime}=M_{t+1}+B_{t+1}-M_{t+1}^{\prime}$ and $\zeta_{t+1}^{\prime}=\left(M_{t+1}^{\prime}, B_{t+1}^{\prime}, B_{H t+1}^{F}, B_{G t+1}^{F}\right)$. Note that $\zeta_{t+1}^{\prime}$ will necessarily satisfy both people's and government's budget constraint. Then, it is a straightforward exercise to show that $\left(\varphi, \chi, \zeta^{\prime}\right)$ satisfies all conditions of a competitive equilibrium.

Proof of Proposition 4: For the 'if part', assume that a competitive equilibrium $(\varphi, \chi, \zeta)$ and a tax system $\xi$ satisfy $(17),(24),(25)$ and $u_{1}(0)=u_{2}(0)$. We need to show that it also respects (1), (13), (20), (21), (23), and (22). The first 
Alexandre B. Cunha

two are trivially satisfied. It was shown in the proof of proposition 2 that

$$
i_{t+1}=0 \Rightarrow u_{1}(t+1)=u_{2}(t+1) .
$$

Since it was assumed that $u_{1}(0)=u_{2}(0),(20)$ is satisfied. Equations (10) and (24) imply (21). Similarly, (11) and (24) imply (23), while (22) can be obtained from (9) and (25).

For the 'only if part', let $(\varphi, \chi, \zeta)$ be a competitive equilibrium and assume that $\chi$ is Pareto efficient. We need to show that (17), (24), (25) and $u_{1}(0)=$ $u_{2}(0)$ hold. The last condition follows directly from (20). Concerning (17), (20) and people's first-order conditions imply $\mu_{t}=0$. This last equality leads to $\lambda_{t}=\lambda_{t+1}$, which in turn implies $i_{t+1}=0$. Equalities (10), (11), (21), and (23) yield (24). Finally, (9) and (22) imply that (25) holds.

Proof of Proposition 5: Let $\chi$ be a Pareto efficient allocation. From Proposition 1, it suffices to show that there exist an initial price level $p_{0}^{N}$ and a sequence $\left\{i_{t+1}, \tau_{t}^{l}, \tau_{t}^{N}, \tau_{t}^{T}, \delta_{t+1}^{F}, \delta_{t}^{N}, \delta_{t}^{T}\right\}_{t=0}^{\infty}$ that satisfy (1) and (9)-(16).

There are several such $p_{0}^{N}$ and $\left\{i_{t+1}, \tau_{t}^{l}, \tau_{t}^{N}, \tau_{t}^{T}, \delta_{t+1}^{F}, \delta_{t}^{N}, \delta_{t}^{T}\right\}_{t=0}^{\infty}$. Of course, it suffices to establish that there exists one. Set $i_{t+1}, \tau_{t}^{N}, \tau_{t}^{T}, \tau_{t}^{l}$ and $\delta_{t}^{F}$ to be constant and to satisfy (17), (24) and (25). Note that this implies $\delta_{t}^{F}=0$. Set $\delta_{t}^{N}=\delta_{t}^{T}$ and constant too. It will soon become clear how to pin down these constant values of $\delta^{N}$ and $\tau^{N}$. Set $p_{0}^{N}$ so that $M_{0}=p_{0}^{N}\left(1+\tau^{N}\right) c_{1,0}^{N}$. It remains to show that (1) and (9)-(16) hold.

Feasibility constraint (1) is trivially satisfied. Since $\chi$ is Pareto efficient, it satisfies (21), (23) and (22). Combine these three constraints with (24) and the fact that tax rates are constant to obtain (9), (10) and (11).

Given the chosen tax rates and price levels, (12) can be written as

$$
\begin{gathered}
\left(1+\tau^{N}\right)\left[\sum_{t=0}^{\infty} \beta^{t} W(t)-u_{1}(0) c_{10}^{N}-u_{2}(0) \frac{\left(1+i_{0}\right) B_{0} c_{1,0}^{N}}{M_{0}}\right]= \\
u_{T}(0)\left(1+i_{0}^{F}\right) B_{H 0}^{F}-\left(1-\delta^{N}\right) \sum_{t=0}^{\infty} \beta^{t} u_{l}(t)\left(\frac{1-\alpha^{T}}{\alpha^{T}} l_{t}^{T}+\frac{1-\alpha^{N}}{\alpha^{N}} l_{t}^{N}\right) .
\end{gathered}
$$

Thus, it is enough to pick values for $\tau^{N}$ and $\delta^{N}$ that satisfy the above equation. Note that constraint (26) ensures that even if $\delta^{N}=0$, it is possible to select a consumption tax rate that satisfies $\tau^{N}>-1$. Definition 2 ensures that (13) holds. The initial price level and taxes rates were chosen so that (14) holds, while (15) follows from (20). Concerning (16), it is enough to recall that $\left\{c_{1 t}^{N}\right\}_{t=0}^{\infty}$ is bounded and that Pareto efficiency requires $\limsup _{t \rightarrow \infty} u_{1}(t)<\infty$.

Proof of Lemma 1: Differentiate both sides of (27) with respect to $c^{T}$ and then with respect to $l$ and $c^{T}$. This yields

$$
\frac{u_{T l}}{u_{T}}=\frac{\frac{\partial^{2} F}{\partial l \partial h}}{\frac{\partial F}{\partial h}} .
$$


The Optimality of the Friedman Rule

Repeat the procedure with $c_{1}^{N}$ and $c_{2}^{N}$. This establishes the first pair of equalities in (28). Moreover,

$$
\frac{u_{T i}}{u_{i}}=\frac{\frac{\partial^{2} F}{\partial h^{2}} \frac{\partial h}{\partial c^{T}}}{\frac{\partial F}{\partial h}}+\frac{\frac{\partial^{2} h}{\partial c^{T} \partial c_{i}^{N}}}{\frac{\partial h}{\partial c_{i}^{N}}}, i=1,2 .
$$

Since $h$ represents homothetic preferences, there exists a function $f$ that satisfies

$$
\frac{\partial h}{\partial c_{1}^{N}}=\frac{\partial h}{\partial c_{2}^{N}} f\left(\frac{c_{1}^{N}}{c_{2}^{N}}\right) \Rightarrow \frac{\partial^{2} h}{\partial c^{T} \partial c_{1}^{N}}=\frac{\partial^{2} h}{\partial c^{T} \partial c_{2}^{N}} f\left(\frac{c_{1}^{N}}{c_{2}^{N}}\right) \Rightarrow \frac{\frac{\partial^{2} h}{\partial c^{T} \partial c_{1}^{N}}}{\frac{\partial h}{\partial c_{1}^{N}}}=\frac{\frac{\partial^{2} h}{\partial c^{T} \partial c_{2}^{N}}}{\frac{\partial h}{\partial c_{2}^{N}}},
$$

and the last equality in (28) is established. Concerning (29), we closely follow Chari, Christiano and Kehoe [3]. If $a$ is any positive real number, then

$$
\frac{u_{1}\left(a c^{T}, a c_{1}^{N}, a c_{2}^{N}, l\right)}{u_{1}\left(c^{T}, c_{1}^{N}, c_{2}^{N}, l\right)}=\frac{u_{2}\left(a c^{T}, a c_{1}^{N}, a c_{2}^{N}, l\right)}{u_{2}\left(c^{T}, c_{1}^{N}, c_{2}^{N}, l\right)} .
$$

Differentiate each fraction in the above expression with respect to $a$ and set $a=1$ to obtain

$$
\frac{u_{T 1}}{u_{1}} c^{T}+\sum_{j=1}^{2} \frac{u_{1 j}}{u_{1}} c_{j}^{N}=\frac{u_{T 2}}{u_{2}} c^{T}+\sum_{j=1}^{2} \frac{u_{2 j}}{u_{2}} c_{j}^{N} .
$$

Equality (29) follows directly from the above expression and (28). Similar reasoning establishes (30).

Proof of Corollary 1: Once more, we assume that $\delta_{t}^{N}=\delta_{t}^{T}=1$. Given the hypothesis on the tax rates, the Ramsey planner can decentralize any attainable allocation by setting $\delta_{t}^{F}$ and $\tau_{t}^{l}$ to satisfy (9) and (11). Consider now the problem of maximizing (4) subject to (1), (31) and (13). As in Proposition 6, its solution will satisfy (16) and $u_{1}(t)=u_{2}(t)$. Hence, it remains to show that it satisfies (10). But this can be achieved with the same reasoning we adopted in Proposition 6 to show that $\tau_{t+1}^{N}=\tau_{t+1}^{T}$.

Details of Remark 1: From the proof of Corollary 1, it should be clear that constraint (10) cannot be omitted from the maximization problem. Write that constraint as

$$
\left(1+\tau_{t}^{N}\right) \alpha^{T}\left(l_{t}^{N}\right)^{1-\alpha^{N}} u_{T}(t)=\left(1+\tau_{t}^{T}\right) \alpha^{N}\left(l_{t}^{T}\right)^{1-\alpha^{T}} u_{2}(t)
$$

Now, maximize (4) subject to (1), (31), (13) and (52). Denote the Lagrange multiplier of this last constraint by $\beta^{t} \rho_{t}$, while $\Gamma$ and $\beta^{t} \gamma_{t}^{N}$ have the previously defined meaning. The first-order conditions for $c_{1 t}^{N}$ and $c_{2 t}^{N}$ can be written as

$$
\frac{\gamma_{t}^{N}}{u_{1}(t)}=(1+\Gamma)+\Gamma\left[\frac{u_{T 1}(t)}{u_{1}(t)} c_{t}^{T}+\frac{u_{11}(t)}{u_{1}(t)} c_{1 t}^{N}+\frac{u_{12}(t)}{u_{1}(t)} c_{2 t}^{N}+\frac{u_{1 l}(t)}{u_{1}(t)} l_{t}\right]-
$$




$$
\rho_{t}\left[\left(1+\tau_{t}^{N}\right) \alpha^{T}\left(l_{t}^{N}\right)^{1-\alpha^{N}} \frac{u_{T 1}(t)}{u_{1}(t)}-\left(1+\tau_{t}^{T}\right) \alpha^{N}\left(l_{t}^{T}\right)^{1-\alpha^{T}} \frac{u_{12}(t)}{u_{1}(t)}\right]
$$

and

$$
\begin{gathered}
\frac{\gamma_{t}^{N}}{u_{2}(t)}=(1+\Gamma)+\Gamma\left[\frac{u_{T 2}(t)}{u_{2}(t)} c_{t}^{T}+\frac{u_{12}(t)}{u_{2}(t)} c_{1 t}^{N}+\frac{u_{22}(t)}{u_{2}(t)} c_{2 t}^{N}+\frac{u_{2 l}(t)}{u_{2}(t)} l_{t}\right]- \\
\rho_{t}\left[\left(1+\tau_{t}^{N}\right) \alpha^{T}\left(l_{t}^{N}\right)^{1-\alpha^{N}} \frac{u_{T 2}(t)}{u_{2}(t)}-\left(1+\tau_{t}^{T}\right) \alpha^{N}\left(l_{t}^{T}\right)^{1-\alpha^{T}} \frac{u_{22}(t)}{u_{2}(t)}\right] .
\end{gathered}
$$

Apply Lemma 1 to obtain

$$
\frac{\gamma_{t}^{N}}{u_{1}(t)}-\frac{\gamma_{t}^{N}}{u_{2}(t)}=\rho_{t}\left(1+\tau_{t}^{T}\right) \alpha^{N}\left(l_{t}^{T}\right)^{1-\alpha^{T}}\left[\frac{u_{12}(t)}{u_{1}(t)}-\frac{u_{22}(t)}{u_{2}(t)}\right]
$$

Clearly, there can be several circumstances in which $u_{1}(t) \neq u_{2}(t)$. For instance, that will happen whenever $u_{12}(t) \geq 0$ and $u_{22}(t)<0$.

Proof of Corollary 2: Without loss of generality, assume that $\delta_{t}^{N}=\delta_{t}^{T}=1$. Consider the problem of maximizing (4) subject to (1), (31) and (13). As in Corollary 1 , the solution will satisfy (20) and (21). It remains to show that it satisfies (22). But we established this fact in Proposition 7.

\section{References}

[1] Carlstrom, C. and Fuerst, T. (2002). Optimal monetary policy in a small open economy: a general equilibrium analysis. In Loayza, N. and SchmidtHebbel, K. (ed.). Monetary Policy: Rules and Transmission Mechanisms. Santiago, Central Bank of Chile.

[2] Cavalcanti, T. and Villamil, A. (2003). Optimal inflation tax and structural reform. Macroeconomic Dynamics 7, 333-362.

[3] Chari, V.; Christiano, L. and Kehoe, P. (1996). Optimality of the Friedman rule in economies with distorting taxes. Journal of Monetary Economics 37, 203-223.

[4] Chari, V. and Kehoe, P. (1999). Optimal fiscal and monetary policy. In Taylor, J. and Woodford, M. (ed.). Handook of Macroeconomics - Volume 1C. Amsterdam, North-Holland.

[5] Cole, H. and Kocherlakota, N. (1998). Zero nominal interest rates: why they are good and how to get them. Federal Reserve Bank of Minneapolis Quarterly Review 22, 2-10.

[6] Correia, I. and Teles, P. (1996). Is the Friedman rule optimal when money is an intermediate good?. Journal of Monetary Economics 38, 223-244. 
The Optimality of the Friedman Rule

[7] Correia, I. and Teles, P. (1999). The optimal inflation tax. Review of Economic Dynamics 2, 325-346

[8] De Fiore, F. and Teles, P. (2003). The optimal mix of taxes on money, consumption and income. Journal of Monetary Economics 50, 871-887.

[9] Friedman, M. (1969). The optimum quantity of money. In: The Optimum Quantity of Money and Other Essays, Aldine, Chicago.

[10] Ireland, P. (2003). Implementing the Friedman rule. Review of Economic Dynamics 6, 120-134.

[11] Kimbrough, K. (1986). The optimum quantity of money in the theory of public finance. Journal of Monetary Economics 18, 277-284.

[12] Lucas, R., Jr. and Stokey, N. (1983). Optimal fiscal and monetary policy in an economy without capital. Journal of Monetary Economics 12, 55-93.

[13] Nicolini, J. (1998). More on the time consistency of monetary policy. Journal of Monetary Economics 41, 333-350.

[14] Phelps, E. (1973). Inflation in the theory of public finance. Swedish Journal of Economics 75, 67-82.

[15] Ramsey, F. (1927). A contribution to the theory of taxation. Economic Journal 37, 47-61.

[16] Schmitt-Grohé, S. and Uribe, M. (2003). Anticipated Ramsey reforms and the uniform taxation principle: the role of international financial markets. National Bureau of Economic Research, working paper 9862.

[17] Schmitt-Grohé, S. and Uribe, M. (2004). Optimal fiscal and monetary policy under sticky prices. Journal of Economic Theory 114, 198-230.

[18] Svensson, L. E. O. (1985). Money and asset prices in a cash-in-advance economy. Journal of Political Economy 93, 919-944.

[19] Wilson, C. (1979). An infinite horizon model with money. In: Green, J. and Scheinkman, J., General Equilibrium, Growth and Trade: Essays in Honor of Lionel McKenzie, Academic Press, New York. 